\title{
Reduction in murine acute GVHD severity by human gingival tissue-derived mesenchymal stem cells via the CD39 pathways
}

\author{
Xuhao Ni $\mathbb{D}^{1,2}$, Yongxiang Xia ${ }^{1}$, Shun Zhou ${ }^{1,3}$, Hao Peng ${ }^{1,2}$, Xiao Wu ${ }^{1,2}$, Hao Lu ${ }^{1,2}$, Han Wang ${ }^{1,2}$, Rui Liu ${ }^{1,2}$,
} Bruce R. Blazar ${ }^{4}$, Jian Gu, ${ }^{1,2}$ and Ling Lu $u^{1,2}$

\begin{abstract}
Human gingival tissue-derived mesenchymal stem cells (GMSCs) present an accessible source of mesenchymal stem cells (MSCs) for treating autoimmune diseases. Here we show that human GMSCs can prevent and treat acute graftversus-host disease (GVHD) in two different mouse models. Our results indicate that besides exhibiting suppressive function in vitro and in vivo, GMSCs may also regulate the conversion of Tregs to Th1 and/or Th17-like cells, as well as stabilize Foxp3 expression. Furthermore, GMSC-mediated prevention of acute GVHD was dependent on CD39 signaling that play an important role in the function and stability of Tregs. Finally, we also observed stronger protective ability of GMSCs with greater expansion ability compared with BMSCs or ASCs. These results indicate that human GMSCs have the potential to be used to treat GVHD.
\end{abstract}

\section{Introduction}

Administration of mesenchymal stem cells (MSCs) represents a promising treatment for patients suffering from autoimmune disorders. Exogenous mesenchymal stem cells have been shown to inhibit $\mathrm{T}$-cell proliferation $^{1}$, as well as improve outcomes in preclinical murine models of $\mathrm{GVHD}^{2}$ and clinical steroid refractory GVHD in children ${ }^{3}$. Use of gingival-derived MSCs (GMSCs)-a population of stem cells that exists in the human gingival tissue-has several advantages over that of bone marrow

Correspondence: Jian Gu (jiangu0304@163.com) or Ling Lu (Ivling@njmu.edu. cn)

${ }^{1}$ Hepatobiliary Center, First Affiliated Hospital, Jiangsu Key Laboratory of Xenotransplantation, Collaborative Innovation Center for Cancer Medicine, Nanjing Medical University, 211166 Nanjing, Jiangsu, China

${ }^{2}$ State Key Laboratory of Reproductive Medicine, Nanjing Medical University, 211166 Nanjing, Jiangsu, China

Full list of author information is available at the end of the article.

These authors contributed equally: Xuhao Ni, Yongxiang Xia, Shun Zhou

Edited by $Y$. Wang stromal cells (BMSCs): easier isolation, better population homogeneity, and more rapid proliferation ${ }^{4}$.

Acute GVHD is a severe complication of allogeneic hematopoietic stem cells and solid organ transplantation that is associated with significant morbidity and mortality. Current strategies to treat acute GVHD do not produce long-lasting responses and vary greatly between different individuals ${ }^{5}$. Thus, developing effective GVHD prevention and treatment strategies is key to improve the state of transplantation medicine.

CD39 is an ectoenzyme that hydrolyzes ATP and adenosine diphosphate (ADP) into adenosine monophosphate (AMP). Located on the surface of endothelial cells and circulating platelets, CD39 plays a role in the suppressive function of human and mouse regulatory $\mathrm{T}$ cells (Tregs) ${ }^{6}$. Previous data from our laboratory demonstrated that CD39 signaling is involved in mediating the protective effect of $\mathrm{GMSCs}^{7}$. Here, we investigated the potential therapeutic effects of GMSCs and the role that CD39

\section{(c) The Author(s) 2019}

(c) Open Access This article is licensed under a Creative Commons Attribution 4.0 International License, which permits use, sharing, adaptation, distribution and reproduction cc) in any medium or format, as long as you give appropriate credit to the original author(s) and the source, provide a link to the Creative Commons license, and indicate if changes were made. The images or other third party material in this article are included in the article's Creative Commons license, unless indicated otherwise in a credit line to the material. If material is not included in the article's Creative Commons license and your intended use is not permitted by statutory regulation or exceeds the permitted use, you will need to obtain permission directly from the copyright holder. To view a copy of this license, visit http://creativecommons.org/licenses/by/4.0/. 
plays in this GMSC-mediated GVHD attenuation. Our data show that human GMSCs have therapeutic potential in ameliorating lethal acute GVHD through adenosine receptors.

\section{Materials and methods \\ Animals}

BALB/c (H-2d), C57BL/6 (H-2b; termed B6), DBA/2 $(\mathrm{H}-2 \mathrm{~d})$, and B6D2F1 (H-2b/d) mice were purchased from Jackson Laboratory (Bar Harbor, ME). C57BL/6 Foxp3GFP-knock-in mice were generously provided by Dr. Talil Chatilla (UCLA) and bred in our animal facility. Mice were used at age of 8-12 weeks. All murine experiments were performed in accordance with protocols approved by the Institutional Animal Care and Use Committees at University of Nanjing Medical University.

\section{GMSCs, BMSCs, and adipose stromal/stem cell (ASC) preparation}

Human gingiva samples were collected following routine dental procedures at Nanjing Medical University, with approval by the Institutional Review Board. Human GMSCs were obtained as previously described ${ }^{4}$.

Human BMSCs were isolated by differential adhesion from a $30 \mathrm{~mL} B M$ aspirate obtained from the iliac crest of two human donors (Lonza, Hopkinton, MA) at the First Affiliated Hospital of Nanjing Medical University in China with approval by the ethics committee of Jiangsu People's Hospital. Mononuclear cells (MNC) were enriched from the BM by using ACK Lysis Buffer (Lonza, Walkersville, MD) and long-term culture. The cells were cultured in MSC growth medium consisting of Minimum Essential Medium Alpha supplemented with 10\% fetal bovine serum (Gibco, Grand Island, NY), 1\% PenicillinStreptomycin (Sigma Aldrich, St. Louis, MO), $2.5 \mu \mathrm{g} / \mathrm{L}$ FGF (R\&D Systems, Minneapolis, MN), $2 \mathrm{ml} / \mathrm{L}$ Gentamicin (Sigma Aldrich, St. Louis, MO), and $2.2 \mathrm{~g} / \mathrm{L}$ $\mathrm{NaHCO} 3$ (Sigma Aldrich, St. Louis, MO) at $37^{\circ} \mathrm{C}$ with $5 \%$ carbon dioxide. On day 5, non-adherent cells were removed, and the growth media was fully replaced. Adherent cells were then expanded for another two weeks. Cells were washed with phosphate-buffered saline (PBS) (Thermo Fisher Scientific Waltham, MA), and the media was replaced on day 14 .

\section{Adipose stromal/stem cell (ASC) preparation}

Following ethics approval by Jiangsu People's Hospital, human ASCs were isolated from donated subcutaneous lip aspirates and tissue from abdominoplasties of two donors using previously described methods ${ }^{8,9}$. Briefly, liposuction tissues were washed with PBS, digested for $1 \mathrm{~h}$ in PBS supplemented with $1 \%$ bovine serum albumin, $0.1 \%$ collagenase type 1 and $2 \mathrm{mM} \mathrm{CaCl}$. The stromal vascular fraction (SVF) was found in the pellet after centrifugation at $300 \mathrm{~g}$ at room temperature. The SVF cells were then expanded in DMEM/F12 Ham's medium supplemented with $10 \%$ fetal bovine serum and $1 \%$ antibiotic/antifungal agents until $>80 \%$ confluent. Adherent ASCs were dislodged from tissue culture flasks using trypsin digestion. The cells were characterized by cell surface immunophenotyping, as well as in vitro (data not shown).

\section{Induction of $\mathrm{CD}^{+}$Tregs in vitro}

Naïve $\mathrm{CD} 4{ }^{+} \mathrm{CD} 25^{-} \mathrm{CD} 62 \mathrm{~L}^{+} \mathrm{T}$ cells were purified from the spleens of Foxp3-GFP C57BL/6 mice via magnetic isolation (Miltenyi Biotec). GMSCs or fibroblast cells were co-cultured with naïve $\mathrm{CD} 4{ }^{+} \mathrm{CD} 25^{-} \mathrm{CD} 2 \mathrm{~L}^{+} \mathrm{T}$ cells (1:5), and stimulated with beads coated with anti-CD3 and CD28 $\mathrm{mAb}(1: 5)$ in the presence of IL-2 $(100 \mathrm{IU} / \mathrm{ml})$ and TGF- $\beta$ ( $5 \mathrm{ng} / \mathrm{ml})$ to induce Tregs. GMSCs and fibroblast cells were allowed to adhere to the plate overnight before the co-culture. In some experiments, rmIL-6 $(10 \mathrm{ng} / \mathrm{mL})$ and/or rmIL-1 $\beta(10 \mathrm{ng} / \mathrm{mL})$ were also added. After 3 days, cells were harvested and analyzed by flow cytometry for CD25, Foxp3, and CD39 expression.

\section{Treg immunosuppression assays}

WT naïve CD4 $+\mathrm{T}$ cells were labeled with CFSE and cultured in a 96-well bottom plate with anti-CD3/CD28conjugated beads or anti-CD3-conjugated beads and APCs at a cell to bead ratio of 1:1. Serially diluted Treg cells were co-cultured for $72 \mathrm{~h}$ and cellular proliferation by CFSE was measured by flow cytometry.

\section{Acute GVHD models}

Model I: BALB/c hosts were given total body irradiation (TBI; 800 cGy) from a $200-K v$ x-ray source. Within $24 \mathrm{~h}$, $\mathrm{BALB} / \mathrm{c}$ mice were intravenously injected with $5 \times 10^{6} \mathrm{~T}$ cell-depleted BM cells and $2 \times 10^{6} \mathrm{~T}$ cells from C57BL/6 mice ${ }^{10,11}$. Mice were given medicated water $(25 \mu \mathrm{g} / \mathrm{ml}$ neomycin $/ 0.3 \mathrm{U} / \mathrm{ml}$ polymyxin B; Sigma-Aldrich) ${ }^{12-16}$. The survival of mice was monitored daily, and body weight was measured weekly.

Model II: Acute GVHD was induced by intravenous injection of $50 \times 10^{6}$ splenocytes isolated from C57BL/6 mice into non-irradiated B6D2F1 mice as previously reported ${ }^{17}$. Mice were sacrificed after 2 weeks, and splenocytes were stained for the expression of $H 2 k^{b}, H 2 k^{d}$, and immune cell lineage markers using flow cytometry $^{18,19}$.

\section{Chimerism assay}

In Model II, mice were sacrificed on day 14, and the spleen cells were examined by flow cytometry. The proportion of donor to host cell was determined by staining $\mathrm{H} 2-\mathrm{K}^{\mathrm{d}}$ and $\mathrm{H} 2-\mathrm{K}^{\mathrm{b}}$ (donor cells are $\mathrm{H} 2-\mathrm{K}^{\mathrm{b}+/ \mathrm{d}-}$; host cells are $\mathrm{H} 2-\mathrm{K}^{\mathrm{b}+/ \mathrm{d}+}$ ). 


\section{In vivo cytotoxic $\mathrm{T}$ cell activity}

In vivo cytotoxic activity was determined using carboxyfluoroscein succinimidyl ester (CFSE, Thermo Fisher Scientific Waltham, MA) labeled target cells as described by manufacturer's protocol. Briefly, spleen cells from DBA/2 mice were stained with $0.5 \mu \mathrm{M}$ CFSE $\left(\right.$ CFSE $\left.^{\text {low }}\right)$ and spleen cells from C57BL/6 mice were stained with $5 \mu \mathrm{M}$ CFSE (CFSE ${ }^{\mathrm{hi}}$ ). F1 mice were injected intravenously with a 1:1 mixture $\left(1 \times 10^{7}\right.$ cells each) from both donors as target cells. CFSE staining density allowed distinction between injected DBA/2 and C57BL/6 cells. Five hours after adoptive cell transfer, mice were sacrificed. Their splenocytes were analyzed by flow cytometry to determine the percentage of $\mathrm{CFSE}^{\text {low }}$ and $\mathrm{CFSE}^{\text {hi }}$ cell populations. The absolute number of each target cell population was calculated based on the total spleen cell counts from individual mice. This number was multiplied by the percentage of CFSE ${ }^{\text {low }}$ and CFSE ${ }^{\text {hi }}$ cells as determined by flow cytometry for each respective mouse. The percent specific lysis was determined using frequency of donor cells: $\%$ lysis $=\left(\% \mathrm{CFSE}^{\text {low }}\right.$ in normal F1-\% CFSE ${ }^{\text {low }}$ in experiments/\%CFSE ${ }^{\text {low }}$ in normal F1 $)^{20}$.

\section{Flow cytometry}

Spleen was prepared and stained with CD3 (Clone $17 \mathrm{~A} 2$ ), CD4 (Clone GK1.5), CD8 (Clone 53-6.7), CD19 (Clone 1D3), CD25 (Clone PC61), CD39 (Clone TU66), IFN- $\gamma$ (Clone XMG1.2), TNF- $\alpha$ (Clone MP6-XT22), IL17A (Clone N49-653), IL-4 (Clone 11B11), IL-10 (Clone JES5 ${ }^{-}$16E3), IL-2 (Clone JES6-5H4), Helios (Clone 22F6), Fas (Clone Jo2), H2Kb (Clone AF6-88.5), H2Kd (Clone SF1-1.1.1) and analyzed on a FACSCalibour and a FACSLSR. Intracellular staining was performed with a Foxp3/Transcription Factor Staining Buffer Set (eBioscience).

\section{Statistical analyses}

All data are represented as the mean \pm SEM. Multiple regression and Student's t-tests were used to determine statistical significance of non-survival data. Survival difference was determined by the Kaplan-Meier log-rank test. $P<0.05$ was considered statistically significant.

\section{Results}

GMSC-induced iTregs exhibit suppressive function in vitro

Previous studies demonstrated that GMSCs can generate induced regulatory $\mathrm{T}$ cells (iTregs) in vivo without altering the natural regulatory $\mathrm{T}$ cell (nTreg) population $^{21}$. iTregs have also been shown to inhibit murine acute GVHD ${ }^{17}$. Therefore, we tested the effect of GMSCs on iTreg generation in vitro. $\mathrm{CD} 4^{+} \mathrm{CD} 25^{-} \mathrm{CD} 62 \mathrm{~L}^{+}$naïve $\mathrm{T}$ cells were purified from C57BL/6 Foxp3-GFP-knock-in mice and co-cultured with GMSCs or fibroblasts $\left(1^{*} 10^{6}: 2 * 10^{5}\right) \quad(5: 1)$ in the presence of anti-mouse
$\mathrm{CD} 3 / \mathrm{CD} 28 \mathrm{mAb}$ beads and IL-2 with or without TGF$\beta$. GMSCs did not affect Foxp3 expression in $\mathrm{CD} 4{ }^{+} \mathrm{CD} 25^{+} \mathrm{T}$ cells cultured for 3 days independently of the presence of TGF- $\beta$ in vitro (Fig. 1a). However, GMSCs increased the proportion of Foxp3-GFP ${ }^{+}$cells coexpressing the CD39 ectonucleotidase when TGF- $\beta$ was also present in the culture (Fig. 1b).

We next assessed the stability of iTregs in response to IL- $1 \beta$ and IL-6, two pro-inflammatory cytokines known to increase the degradation of Foxp3 and convert Tregs in effector $\mathrm{T}$ cells. After 3 days, iTregs were purified from the coculture containing GMSCs or fibroblasts using anti$\mathrm{CD} 4 \mathrm{mAb}$-conjugated beads. The cells were then cultured with DMSO or IL- $1 \beta$ and IL- 6 for additional 3 days in the presence of IL-2. As predicted, Foxp3 expression was reduced in the fibroblast-containing iTreg group upon exposure to IL-1 $\beta$ and IL-6 (Fig. 1c), while the GMSCcontaining iTreg group resisted Foxp3 downregulation. Also, the frequencies of IL-17A and IFN- $\gamma$ in the fibroblast-containing iTreg group was higher than in the GMSC-containing iTreg group (Fig. 1c). The effect of IL$1 \beta$ and IL- 6 on iTreg function was also examined. iTregs purified as described above were co-cultured with CFSElabeled $\mathrm{CD} 4^{+} \mathrm{T}$ cells $\left(2^{*} 10^{4}: 8^{*} 10^{4}\right)(1: 4)$ for 3 days, and then analyzed by flow cytometry. Whereas iTregs previously cocultured with GMSCs and fibroblasts both showed similar ability to suppress T-cell expansion under normal conditions, only the fibroblast-induced iTregs lost their suppressive function following exposure to IL-1 and IL-6 (Fig. 1d).

\section{Administration of GMSCs improves survival and reduces pro-inflammatory cytokine production in acute GVHD in vivo}

Next, we examined whether GMSCs can effectively eliminate acute GVHD in vivo. To accomplish this, two different acute GVHD models (C57BL/6-to-BALB/c and C57BL/6-to-B6D2F1) were used. In the C57BL/6-to$\mathrm{BALB} / \mathrm{c}$ model, mice were lethally irradiated and then rescued with an allogeneic donor BM. $2 \times 10^{6}$ GMSCs or fibroblast cells were injected the same day as acute GVHD was induced. Mortality and weight loss were used to quantify progression of acute GVHD as previously described $^{22,23}$. Recipients of GMSCs showed significantly improved survival (Fig. 2 a, $87 \%$ vs. $0 \%, P<0.0001$ ) and weight loss (Fig. 2b; $P<0.031$ ) compared to the nontreated or fibroblast-treated control groups. When GMSCs were injected 7 days after BM transplantation, a strong immunosuppressive environment ensued, with $87 \%$ long-term survival compared to $0 \%$ in the nontreated or fibroblast cell treated controls. These results indicated that exogenous GMSCs were effective in treating acute GVHD (Fig. 2b, $87 \%$ vs. $0 \%, P<0.0025$; Fig. 2d, $P=0.03)$. Because GMSCs enhanced CD39 expression in 
A

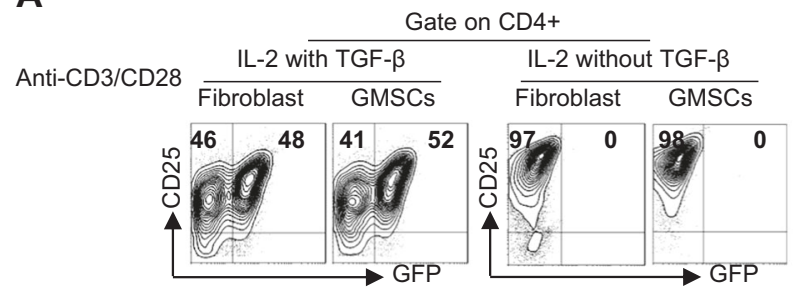

- Fibroblast a GMSCs

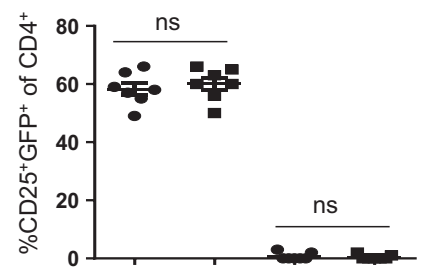

B
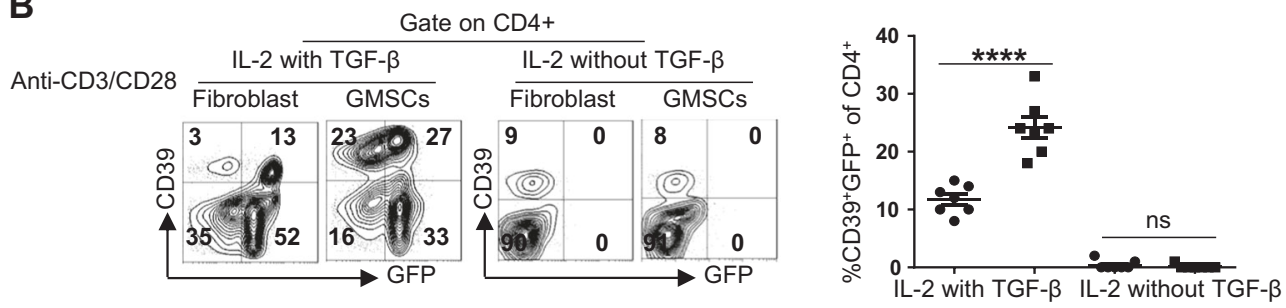

C

Anti-CD3/CD28 $\frac{\mathrm{IL}-1 \beta \text { and IL-6 }}{\text { Cibroblast }}$ With IL-2
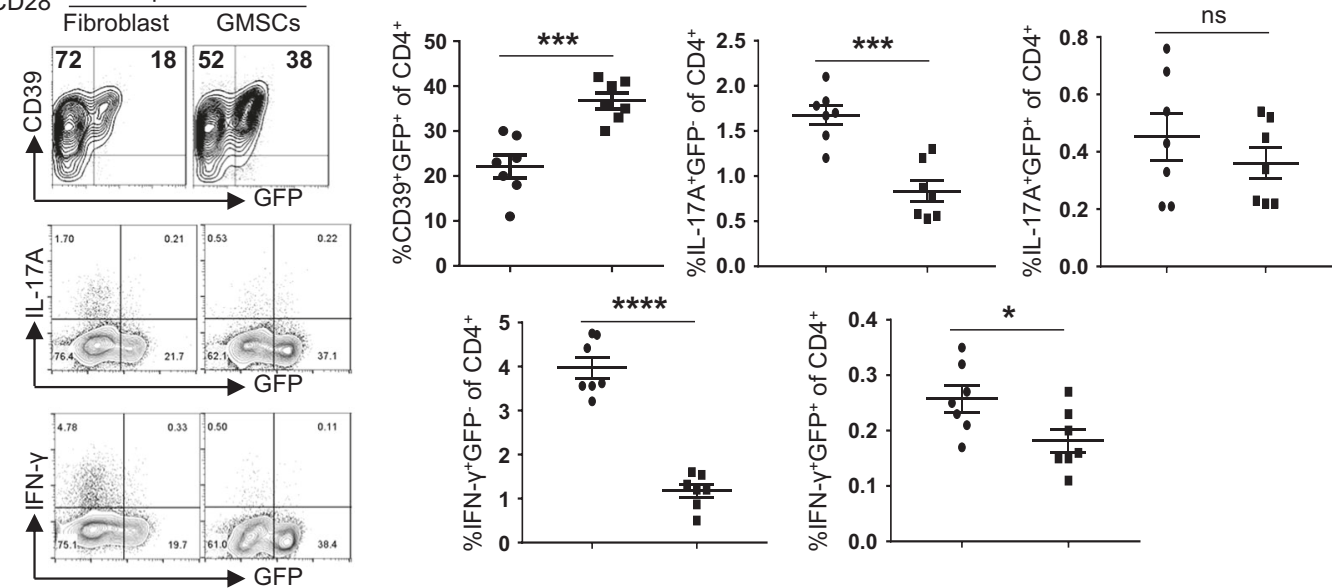

D

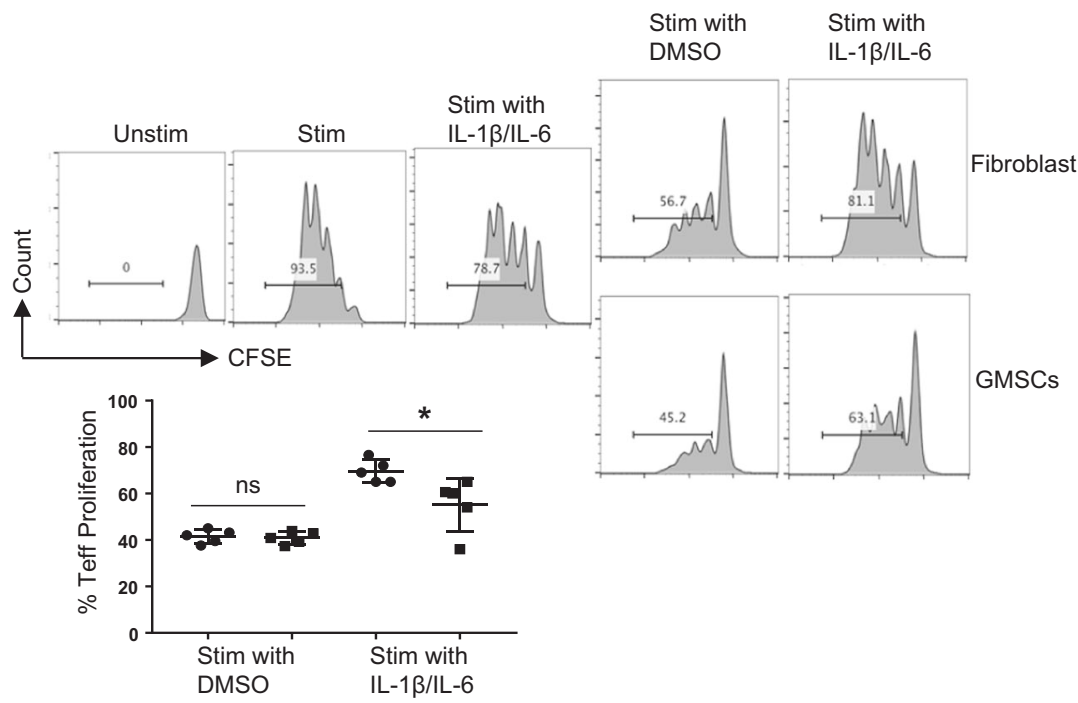

Fig. 1 (See legend on next page.) 
(see figure on previous page)

Fig. 1 GMSCs stabilized Foxp3 expression and enhanced the suppressive function of CD4 ${ }^{+}$iTreg cells in the presence of IL- $1 \beta / \mathrm{IL}-6$ in vitro. a Naiive CD4 + T cells obtained from spleens were induced for 3 days with anti-CD3 mAb $(2 \mathrm{ug} / \mathrm{ml})$ coating the wells and free anti-CD28 mAb $(2 \mathrm{ug} /$ $\mathrm{ml})$, IL-2 $(100 \mathrm{U} / \mathrm{ml})$, with or without TGF- $\beta(5 \mathrm{ng} / \mathrm{ml})$. Representative contour plots of CD25+Foxp3-GFP ${ }^{+}$subset within CD4 ${ }^{+}$iTreg population in the presence of GMSC or fibroblast cells in vitro. Each symbol represents one independent experiments; ns, no significance, unpaired $t$ test.

b Representative contour plots of and CD39 ${ }^{+}$Foxp3-GFP+ subset within $\mathrm{CD}^{+}$iTreg population in the presence of GMSC or fibroblast cells in vitro. Each symbol represents one independent experiments; ${ }^{* * *} P<0.0001$, ns no significance, unpaired $t$ test. $\mathbf{c}$ iTreg cells induced in the presence of GMSCs or fibroblasts were expanded with IL-2, IL-1 $\beta$ and IL-6. Contour plots show CD39 vs. Foxp3-GFP, IL17A vs. Foxp3-GFP and IFN-үvs. Foxp3, the percentage of CD39+Foxp3-GFP ${ }^{+}$cells, IL17A ${ }^{+}$Foxp3-GFP ${ }^{+}$cells, IL17A ${ }^{+}$Foxp3-GFP ${ }^{-}$cells, IFN- $\gamma^{+}$Foxp3-GFP ${ }^{+}$cells, and IFN- $\gamma^{+}$Foxp3-GFP ${ }^{-}$cells were measured. Each symbol represents one independent experiments; ${ }^{*} P<0.05,{ }^{* *} P<0.01$, ${ }^{* * *} P<0.001$, ns, no significance, unpaired $t$ test. d CFSElabeled $\mathrm{CD}^{+} \mathrm{T}$ cells were co-cultured with both iTreg subsets at a 1:4 (2*104:8*104) ratio and anti-CD3 mAb-conjugated beads for 3 days. Cells were then stained with anti-mouse CD4 antibody and analyzed by flow cytometry. Each symbol represents one independent experiments; ${ }^{*} P<0.05$, ns no significance, unpaired $t$ test

iTregs in vitro (Fig. 1) and Tregs can suppress acute $\mathrm{GVHD}^{24}$, we examined the frequency of CD39+ iTregs in this model. Compared with the fibroblast-treated group, the proportion of $\mathrm{CD} 9^{+} \mathrm{Foxp}^{+}$cells was significantly increased in the GMSC-treated group on day 15 (Fig. 2e). Most of these Foxp $3^{+}$cells were Helios ${ }^{-}$iTregs, and no significant difference in the frequency of $\mathrm{Helios}^{+}$nTregs was observed between the treatment groups on day 3 and day15 (Fig. 2f). We investigated why severity of acute GVHD was reduced in our murine models of the disease. Previous studies have suggested that cytokine production by donor cells contributed to the progression of acute GVHD $^{25,26}$. To determine whether GMSCs could suppress acute GVHD through controlling cytokine production by staining with IFN- $\gamma$, IL-17, IL-4, TNF- $\alpha$, IL-2, and IL-10, we detected the production of cytokines after injecting 15 days. Injection of GMSCs into mice with acute GVHD significantly reduced the percentages of cells secreting pro-inflammatory cytokines such as IFN- $\gamma$, IL17 , IL-4, and TNF- $\alpha$. However, the IL-2 production was significantly increased in GMSCs group than Fibroblast group, which suggested that GMSCs can increased the differentiation and function of iTreg through enhancing the secretory of IL-2. Other Th2 cytokines such as IL-5 and IL-13 were undetectable in this model, and iTreg treatment did not alter their levels (data not shown) (Fig. 2g).

In Model II of parent-into-F1 hybrid strain combination [C57BL/6-to-B6D2F1], $50 \times 10^{6}$ C57BL/6 spleen cells were intravenously injected into non-irradiated immunocompetent D2B6F1 mice. After 14 days, mice were sacrificed, and the spleen cells were examined by flow cytometry. Donor and host cells can be distinguished by staining $\mathrm{H} 2 \mathrm{k}^{\mathrm{d}}$ and $\mathrm{H} 2 \mathrm{k}^{\mathrm{b}}$ since donor cells are $\mathrm{H} 2 \mathrm{k}^{\mathrm{b}+} / \mathrm{k}^{\mathrm{d}-}$ and host cells are $\mathrm{H}_{2} \mathrm{k}^{\mathrm{b}+} / \mathrm{k}^{\mathrm{d}+}$. Nearly $50 \%$ of the administered donor cells were found in acute GVHD 2 weeks after adoptive cell transfer. Co-transfer of GMSCs markedly reduced donor engraftment and cell number (Fig. 3a). GMSCs suppressed the expansion of both donor $\mathrm{CD}^{+}$and $\mathrm{CD}^{+}{ }^{+} \mathrm{T}$ cells. Host B cells, which are highly sensitive to depletion during active GVHD, were abundant in GMSC-treated mice compared to untreated GVHD controls and fibroblast-treated recipients (Fig. 3b). We attributed this observation to decreased FasL expression on donor $\mathrm{CD}^{+} \mathrm{T}$ cells and decreased Fas expression on host B cells (Fig. 3b) in GMSC-treated mice $^{27}$.

To determine whether GMSCs suppressed the cytotoxic capacity of donor $\mathrm{T}$ cells, CFSE ${ }^{\text {hi }}$-labeled C57BL/6 and $\mathrm{CFSE}^{\text {low }}$-labeled DBA/2 splenocytes were mixed at a 1:1 ratio and administered in vivo with or without GMSCs $^{20,28}$. After five hours, an approximately equal ratio of $\mathrm{CFSE}^{\text {hi }}$-labeled $\mathrm{B} 6$ and $\mathrm{CFSE}^{\text {low }}$-labeled DBA/ 2 splenocytes was recovered in the GMSC-treated group of non-transplanted F1 mice (Fig. 3c). In contrast, only $40 \%$ of DBA/2 cells were found in the untreated GVHD group. These results suggested selective killing of DBA/2 cells, while administration of GMSCs prevented the CTL priming response of $\mathrm{F} 1$ recipients against donor splenocytes.

\section{iTregs play a role in GMSC-mediated protection against acute GVHD in vivo}

To better understand the role of Tregs in GMSCmediated protection against acute GVHD, we blocked Treg function by treating recipients in our GVHD Model I with an anti-CD25 antibody (clone PC61) ${ }^{29,30}$. PC61 was injected (IP) on the same day as BM and T cell transfer (IV) into the C57BL/6-to-BALB/c model. PC61 abrogated the protective effects of GMSCs during acute GVHD (Fig. 4 a, $73 \%$ vs. $26 \%, P=0.03$; Fig. $4 \mathrm{~b}, P=0.025$ ).

Because GMSCs enhanced $\mathrm{CD} 4^{+}$iTreg suppressive function without affecting Foxp3 expression in vitro (Fig. 1a), we studied the function of GMSC- and fibroblast-primed iTregs in vivo. GMSCs or fibroblasts were co-cultured with $\mathrm{CD} 4{ }^{+} \mathrm{CD} 25^{+} \mathrm{CD} 62 \mathrm{~L}^{+}$Naive $\mathrm{T}$ cells in the presence of TGF- $\beta$ and IL- 2 for 3 days to generate iTregs. Then, $2 \times 10^{6}$ pretreated iTregs were purified by depleting the GMSCs or fibroblasts using anti-CD4-beads. These cells were injected into acute GVHD Model I. We observed that only GMSC-primed iTregs conferred protection against acute GVHD (Fig. 4c, d). 


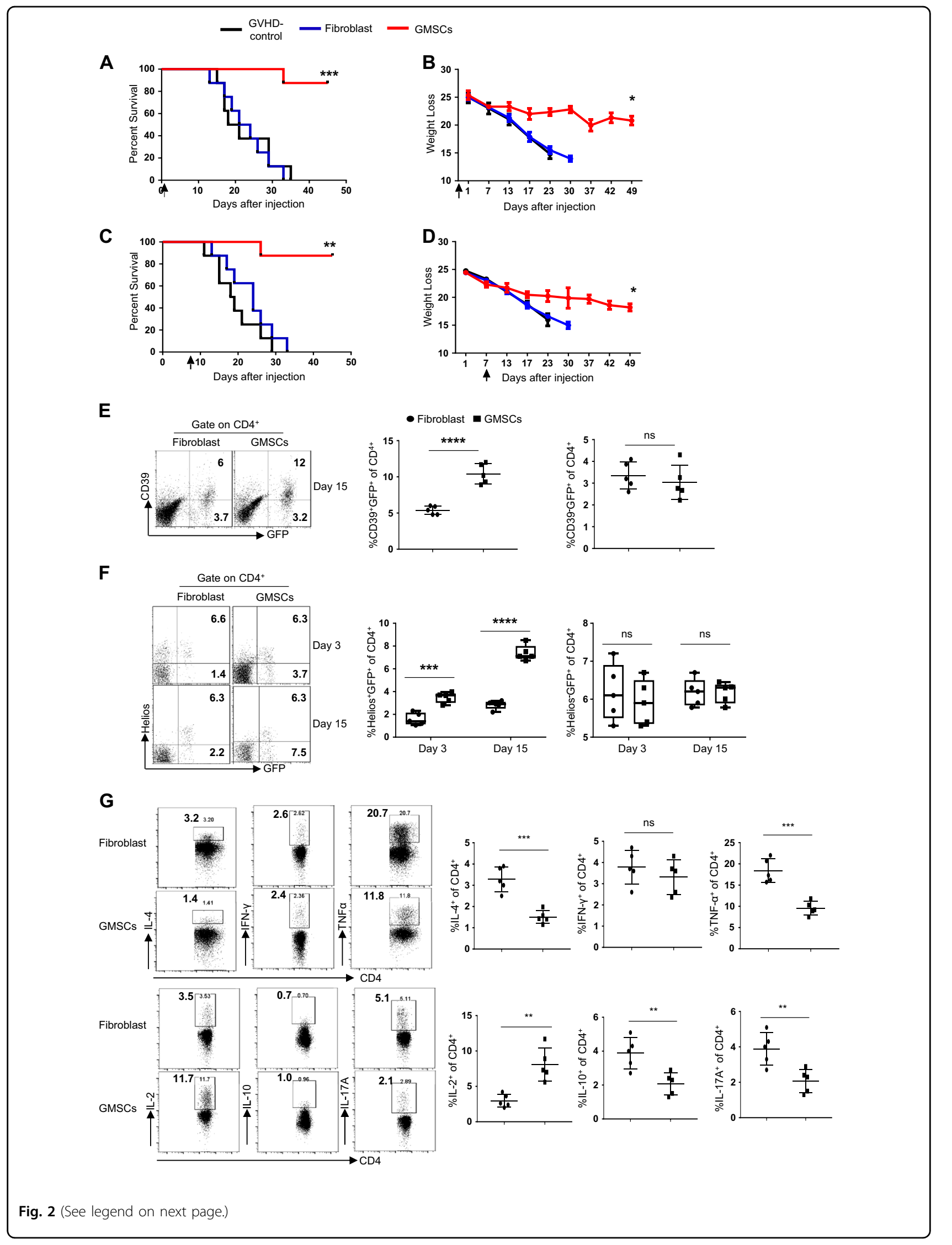


(see figure on previous page)

Fig. 2 Injection of GMSCs, but not fibroblasts, decreased acute GVHD severity. Irradiated BALB/C mice were transplanted with T cell-depleted BM cells and $\mathrm{CD}^{+}$splenic T cells alone (BM only) with or without $2 \times 10^{6} \mathrm{GMSC}$ or fibroblasts. a Recipient survival curve after GMSC or fibroblasts transfer on day 0 . The number of mice is 8 for each group and three independent experiments was performed. ${ }^{* * *} P<0.001$, Log-rank (Mantel-Cox) Test. b Recipient weight loss curve after GMSC or fibroblasts transfer on day 0 . the number of mice is 8 for each group and three independent experiments was performed. ${ }^{*} P<0.05$, unpaired $t$ test. $\mathbf{c}$ Recipient survival curve after GMSC or fibroblasts transfer on day 7 . The number of mice is 8 for each group and three independent experiments was performed. ${ }^{*} P<0.01$, Log-rank (Mantel-Cox) Test. $\mathbf{d}$ Recipient weight loss curve after GMSC or fibroblasts transfer on day 7 . The number of mice is 8 for each group and three independent experiments was performed. ${ }^{*} P<0.05$, unpaired $t$ test. e CD39 vs. Foxp3-GFP expression in CD4 ${ }^{+} \mathrm{T}$ cells from the GMSCs group and Fibroblasts group. Each symbol represents one mouse and three independent experiments was performed. ${ }^{* * *} P<0.0001$, ns, no significance, unpaired $t$ test. $\mathbf{f}$ Helios vs. Foxp3-GFP expression in CD4 ${ }^{+} T$ cells from the GMSCs group and Fibroblasts group. Each symbol represents one mouse and three independent experiments was performed. ${ }^{* * *} P<0.001 ;{ }^{* * * *} P$ $<0.0001$, ns, no significance, unpaired $t$ test. $g$ Expression of IL-4, IL-17, IL-10, IFN- - , IL-2, and TNF-a by CD4 ${ }^{+}$cells were determined by flow cytometry. Data are representative of three independent experiments. ${ }^{* *} P<0.001$; ${ }^{* * *} P<0.0001$, ns no significance, unpaired $t$ test

\section{CD39 pathways are involved in GMSC-induced GVHD attenuation}

Previous studies showed that POM-1, a CD39 inhibitor, diminished the ability of GMSCs to suppress Tcell expansion in vitro ${ }^{21}$. Consistently with this finding, our in vitro experiments demonstrate an increase in Foxp $3^{+} \mathrm{CD} 39^{+}$iTregs in the presence of GMSCs (Fig. 1b). To confirm that CD39 is involved in GMSCmediated GVHD attenuation, we assessed the effect of POM-1 treatment on GMSCs. The GMSCs were treated with POM-1 or isotype control for $4 \mathrm{~h}$ prior to injection into the GVHD Model I. We observed that the protective effect of GMSCs in acute GVHD was substantially reduced following treatment with POM-1 in vitro (Fig. 5a, b), suggesting that CD39 plays an important role in this process. Meantime, we measured the frequency of $\mathrm{CD} 4^{+} \mathrm{Foxp} 3^{+} \mathrm{CD} 39^{+}, \mathrm{CD} 4^{+} \mathrm{IL}-17^{+}$and $\mathrm{CD} 4^{+} \mathrm{IFN}^{-} \gamma^{+}$cells among control group, POM-1+ GMSCs group and GMSCs group. We found that GMSCs increased Treg function through the CD39 pathways (Fig. 5c). We further calculated the correlation between the frequency of $\mathrm{CD}_{3} 9^{+}$or $\mathrm{CD} 39^{-}$Treg and the score of aGVHD and found that only CD39 ${ }^{+}$Treg can affect the progression of aGVHD (Fig. 5c). In order to test whether POM-1 can abrogate the effect of GMSCs on Treg function. We used GMSCs and POM$1+$ GMSCs induced Tregs to suppress the differentiation of Naïve CD4+ T cells in vito. We found that POM$1+$ GMSCs induced Tregs failed to suppress the $\mathrm{T}$ cell responses (Fig. 5d). Meanwhile, we compared the immunosuppressive capacity between Foxp $^{+} \mathrm{CD} 39^{+}$ Treg and Foxp $3^{+} \mathrm{CD} 39^{-}$Treg by co-culturing $\mathrm{CD} 4^{+}$ Naïve $\mathrm{T}$ cells labeled with CFSE and Foxp $3^{+} \mathrm{CD} 39^{+}$ Treg, Foxp $3^{+} \mathrm{CD} 39^{-}$Treg sorted from Control group 3 days in present of anti-CD3 and APCs. The proliferation of $\mathrm{CD}_{4}^{+} \mathrm{T}$ cells was measured after staining with CD4, Foxp $3^{+} \mathrm{CD} 39^{+}$Treg had more function than Foxp $3^{+} \mathrm{CD} 39^{-}$Treg (Fig. 5e). We also examined the expression of those effector molecular that played a critical role in the Treg function between Foxp $3^{+} \mathrm{CD} 39^{+}$ Treg and Foxp $3^{+}$CD39- $9^{-}$Treg, such as CD25, CTLA-4, GITR, CD62L. Our data shown that the expression of CD25, CTLA-4, and GITR in Foxp $3^{+} \mathrm{CD} 39^{+}$Treg were higher than Foxp $3^{+}$CD $39^{-}$Treg (Fig. 5f).

\section{GMSCs showed greater in vitro expansion capacity and stronger GVHD suppressive ability compared to BMSCs or ASCs}

We and others have shown that human GMSCs, BMSCs, and ASCs display similar immunomodulatory properties such as inhibition of the activation and proliferation of human $\mathrm{T}$ cells. Because most MSCs are not functional at later passages and their expansion is limited, they lack potential for treatment of acute GVHD. Thus, we evaluated the expansion and suppression capabilities of GMSCs compared to BMSCs and ASCs by flow cytometry. GMSCs exhibited greater expansion following six in vitro passages compared to both BMSCs and ASCs (Fig. 6a). To evaluate the suppressive ability of these three cell types, each was co-cultured with mouse $\mathrm{CD} 4^{+}$Naïve $\mathrm{T}$ cells at a ratio of 1:20 at different passages. Irradiated non-T cells and anti-CD3 Ab were added. Proliferation was analyzed 3 days after $\mathrm{T}$ cell stimulation. Whereas all three mesenchymal stromal cell types inhibited $\mathrm{CD} 4^{+} \mathrm{T}$ cell proliferation, GMSCs exhibited stronger suppressive ability compared to BMSCs and ASCs, especially after more passages (Fig. 6b). To test the function of the three cell subsets in vivo, we injected the three MSCs from passage 6 into the acute GVHD model. Although all three subsets elicited protection against acute GVHD, treatment with GMSCs resulted in highest survival rate (Fig. 6c).

\section{Discussion}

GMSCs have been shown to be efficacious in different disease models, including collagen-induced arthritis ${ }^{21}$, colitis $^{31-33}$, wound healing ${ }^{34}$, and Xeno-Graftversus-Host Disease ${ }^{35}$. However, no group has yet 

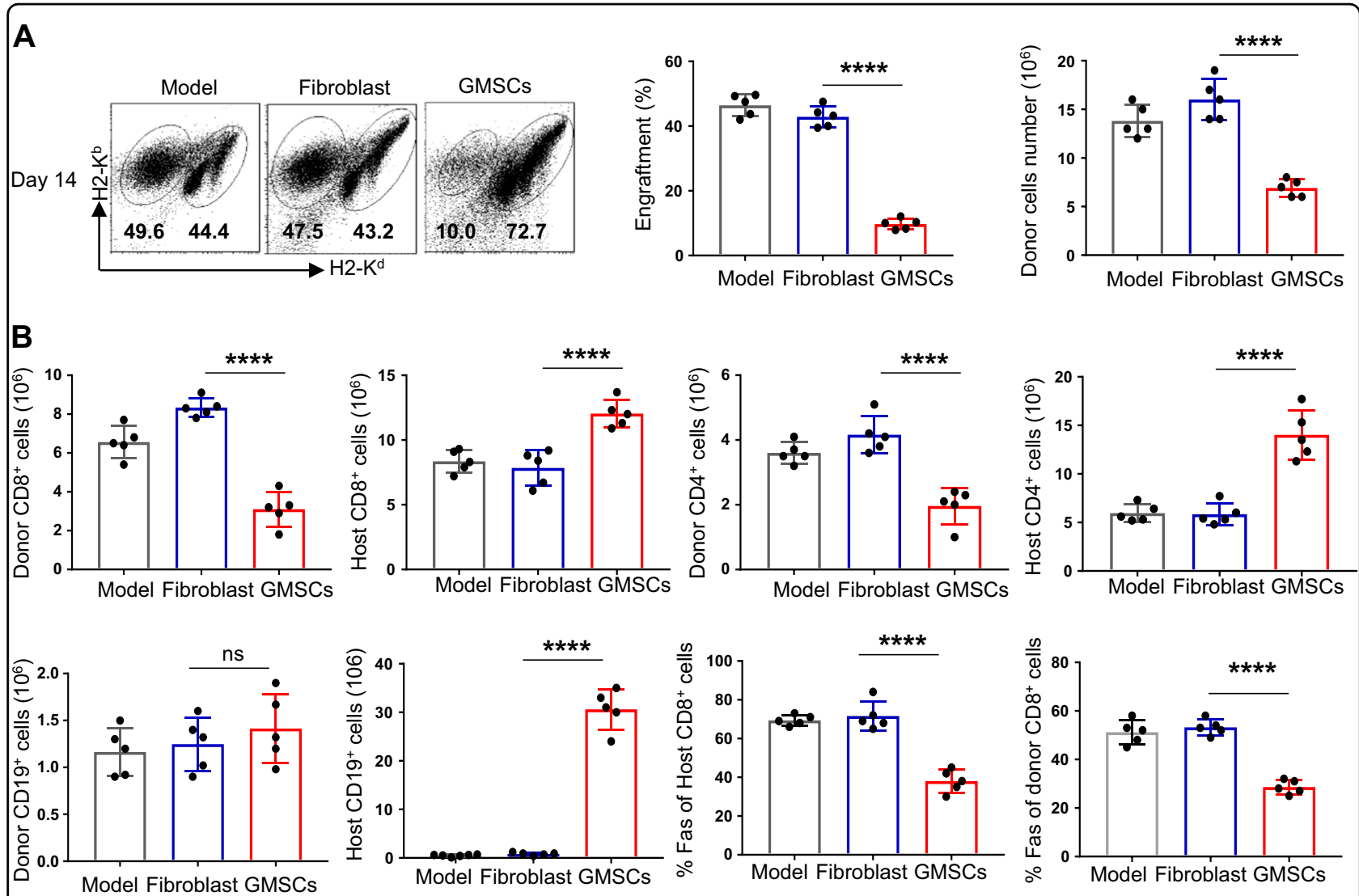

C
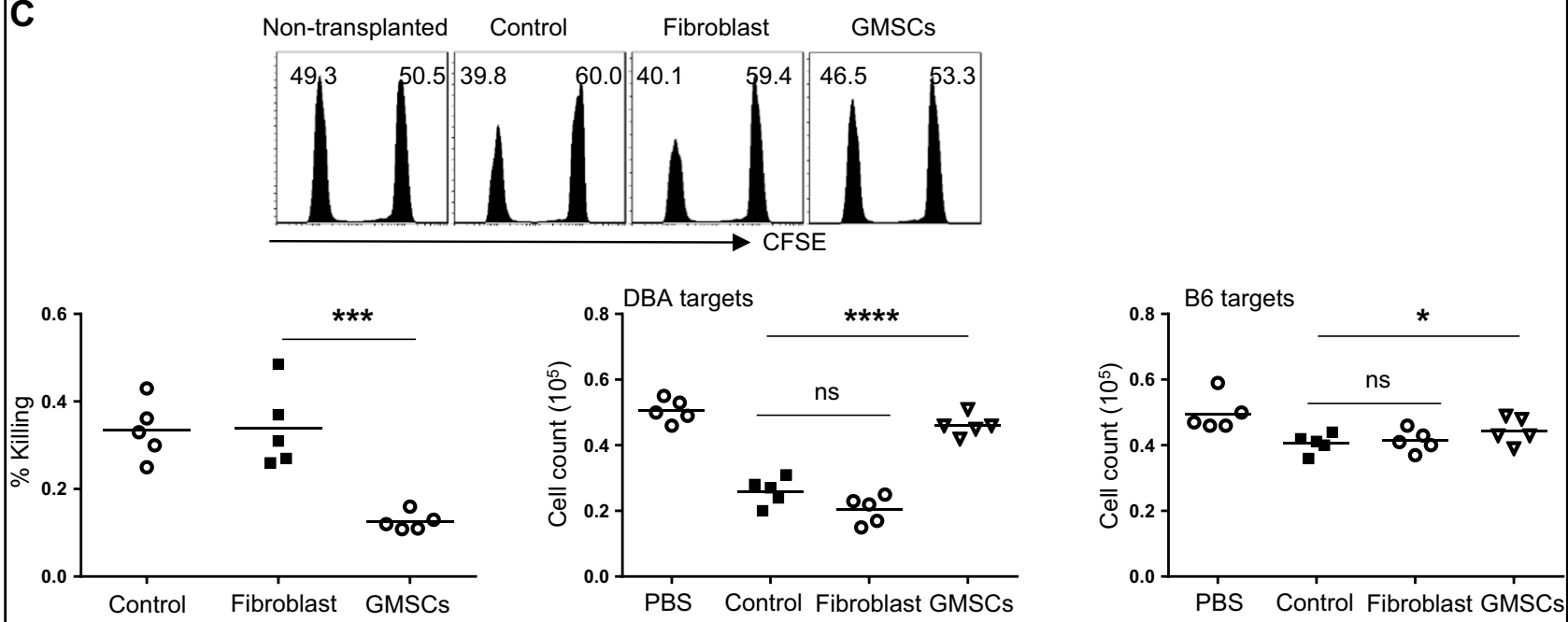

Fig. 3 Adoptive transfer of GMSCs markedly suppressed the engraftment of donor cells in model two of acute-GVHD. Acute-GVHD (C57BL/ 6-to-F1) was induced as described in Methods. After two weeks, mice were sacrificed; donor and host splenic lymphocyte subsets were analyzed by flow cytometry. Donor and host cells can be distinguished by staining $\mathrm{H} 2-\mathrm{Kd}$ and $\mathrm{H} 2-\mathrm{Kb}$ - donor cells are $\mathrm{H}_{2}-\mathrm{Kb}^{+} / \mathrm{d}^{-}$and host cells are $\mathrm{H} 2-\mathrm{Kb}^{+} / \mathrm{d}^{+}$. a $\mathrm{H} 2-\mathrm{Kb}$ vs. $\mathrm{H} 2-\mathrm{Kd}$ for donor and host cells after 14 days. Relative engraftment and absolute numbers of donor cells are shown for each group. Each symbol represents one mouse and two independent experiments was performed. ${ }^{* * *} P<0.0001$, unpaired $t$ test. $\mathbf{b}$ Absolute number of donor CD $8^{+}$ cells; host $\mathrm{CD} 8^{+}$cells, donor $\mathrm{CD} 4^{+}$cells; host $\mathrm{CD}^{+}$cells; donor $\mathrm{CD} 19^{+}$cells; host CD19 $9^{+}$cells; donor Fas ${ }^{+}$in $\mathrm{CD}^{+}$cells; host Fas ${ }^{+}$in $\mathrm{CD}^{+}$cells. Each symbol represents one mouse and two independent experiments was performed. ${ }^{* * *} P<0.0001$, ns, no significance, unpaired $t$ test. c CSFE (CFSE ${ }^{\text {hi }}$ and CSFE ${ }^{\text {low }}$ ) was determined by Flow cytometry, and cells number from DBA targets and B6 targets was counted. Each symbol represents one independent experiments. ${ }^{*} P<0.0001,{ }^{* * *} P<0.0001,{ }^{* * *} P<0.0001$, unpaired $t$ test 

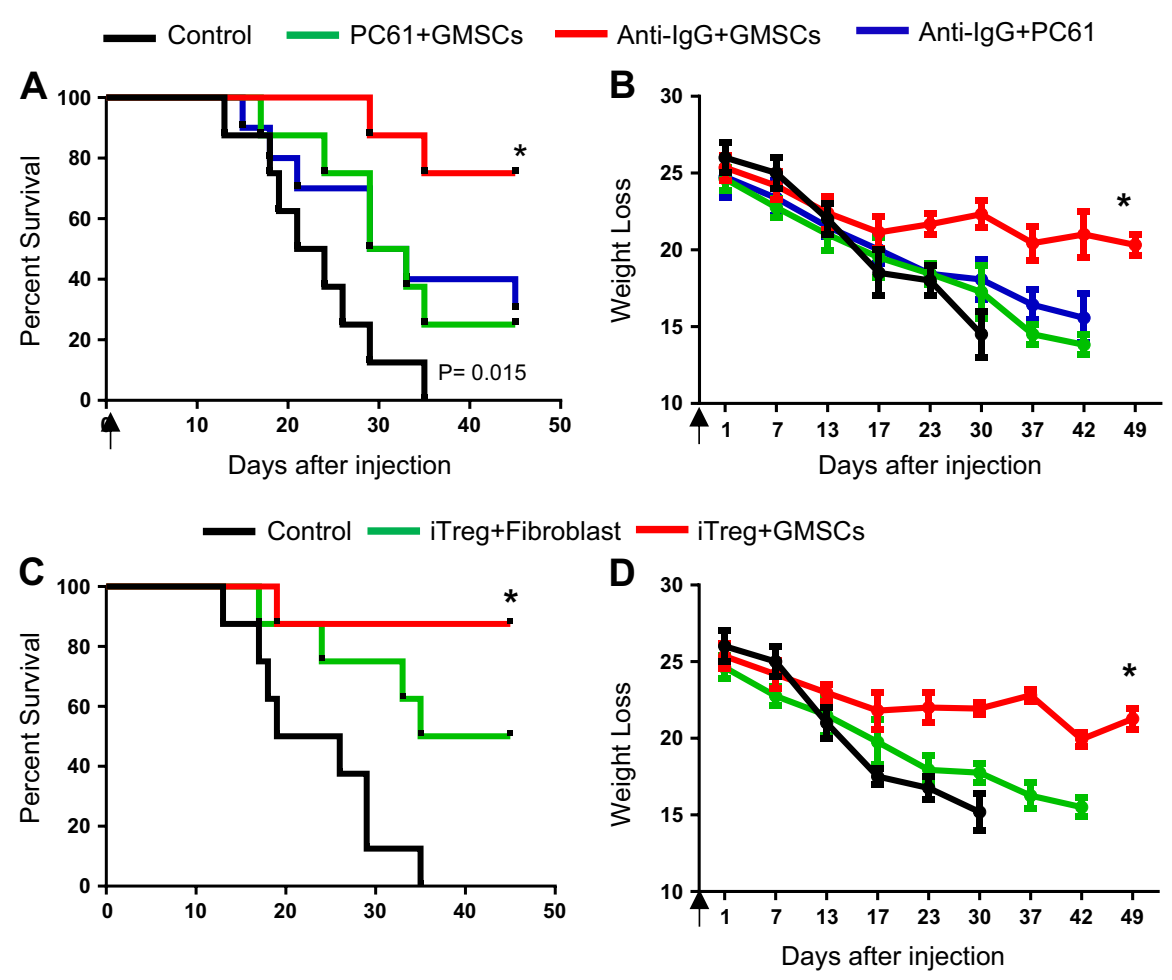

Fig. 4 iTregs play a role in GMSC-mediated protection against acute GVHD in vivo. a Weight loss and (b) survival of acute GVHD mice that received GMSCs in the presence or absence of anti-CD25 mAb (clone PC61), which was administered to deplete Tregs. $\mathbf{c}$ Weight loss and (d) survival of acute GVHD mice receiving GMSC- or fibroblast-primed iTregs on day 0 are shown. The number of mice is 5 for each group and three independent experiments was performed. ${ }^{*} P<0.05$; ${ }^{* *} P<0.01$; ${ }^{* * *} P<0.0001$, Log-rank (Mantel-Cox) Test for survival curve and unpaired $t$ test for weight loss curve

reported that GMSCs can be used to treat acute GVHD. To answer this question, GMSCs were derived from human gingival tissues. Two distinct acute GVHD models were used to monitor GMSCs treatment. Our results clearly demonstrated that the superior effect of GMSCs in reducing the severity of acute GVHD generation and in treating mice with ongoing GVHD

Several factors may explain the mechanism by which GMSCs suppress acute GVHD. First, GMSCs reduced levels of several pro-inflammatory cytokines, particularly IL-17, IL-4, and IFN- $\gamma$, while increased levels of IL-2 which play a important role in the differentiation and function of iTreg. Second, GMSCs inhibited the proliferation of donor $\mathrm{CD} 8$ cells and reduced the cytotoxicity of donor CD8 cells to host CD19 cells. Furthermore, GMSCs reduced the expression of Fas on B cells and FasL on CD8 cells, which prevented killing of target B cells. Therefore, it appears that GMSCs protected the donor cells from apoptosis. Third, we detected higher expression of Foxp3 in GMSC-primed group compared to fibroblast controls in our acute GVHD model. Additionally, although GMSCs did not enhance Foxp3 expression in vitro, GMSCs increased the stability of Foxp3 expression and sustained the suppressive function of CD4 iTregs under inflammatory conditions.

Multiple studies have shown that the immunoregulatory function of GMSCs is associated with higher Treg frequency in vivo ${ }^{36,37}$. A population of Foxp $3^{+} \mathrm{CD} 39^{+}$iTregs is highly expressed in TGF- $\beta$-generated $\mathrm{CD} 4^{+}$iTregs as a result of adding GMSCs to cell cultures in vitro; indeed, GMSCs were identified as having stronger regulatory function and stability ${ }^{38}$. We also detected higher Foxp3 expression in the GMSC-primed group compared to the Fibroblast-primed group, and most of the Foxp $3^{+}$cells were lacked Helios expression. In addition, our experiments showed that, although GMSCs had no effect on Foxp3 expression, GMSCs increased the stability of Foxp3 expression and sustained the suppressive function of $\mathrm{CD} 4{ }^{+}$iTregs during the inflammatory response.

Recently, a population of $\mathrm{CD} 4^{+} \mathrm{CD} 39^{+} \mathrm{Foxp}^{+} \mathrm{T}$ cells was identified as having a regulatory function in the autoimmune disease model ${ }^{39}$. Our results suggest that Helios ${ }^{-}$Foxp $^{+} \mathrm{T}$ cells are a unique cell population that may be induced by GMSCs in acute GVHD. Interestingly, while the number of Treg cells as defined by Foxp3 expression did not increase, the survival of GMSC-treated 


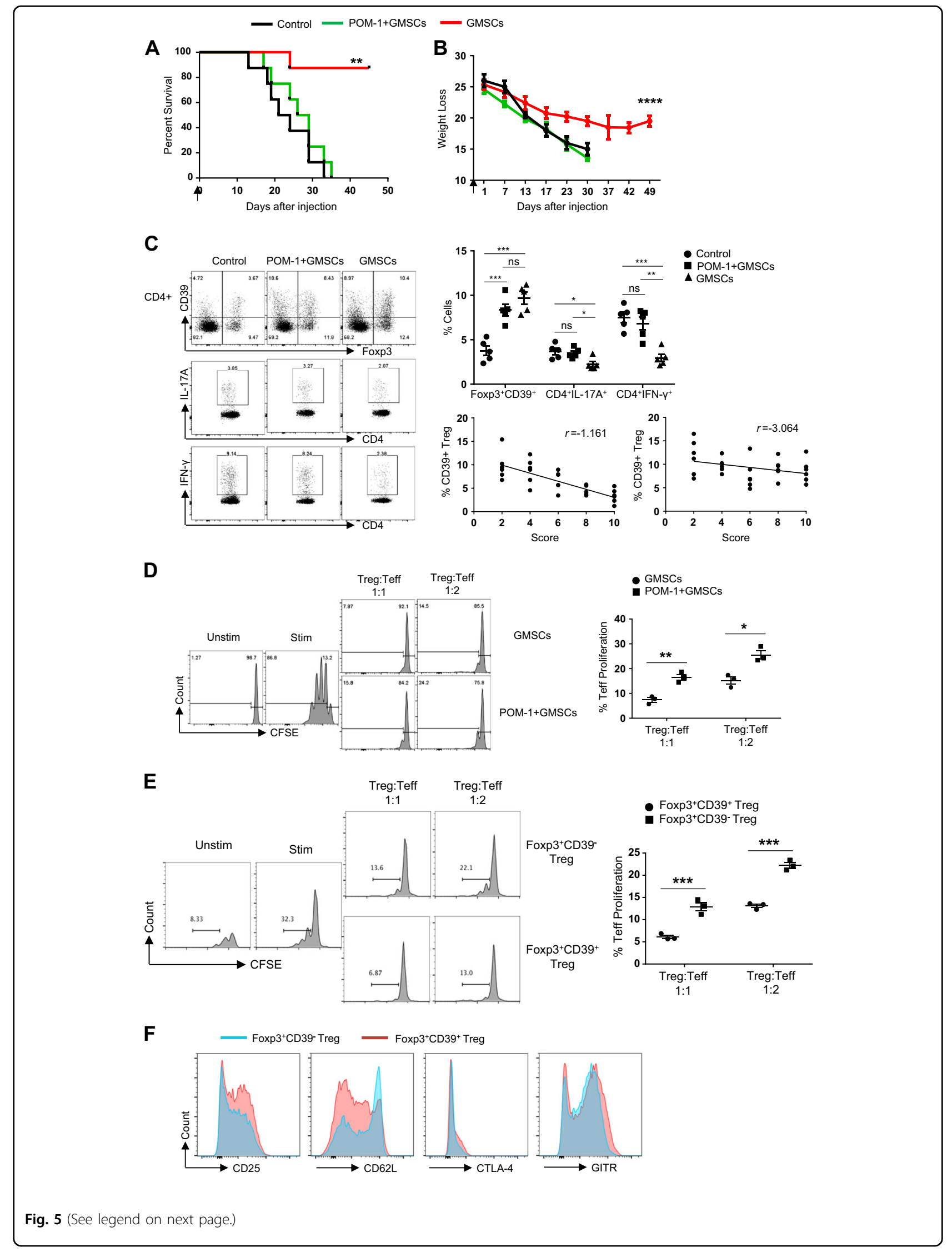


(see figure on previous page)

Fig. 5 CD39 pathways are involved in GMSC-induced GVHD attenuation. a Weight loss and (b) survival of mice that received GMSCs pretreated or not treated with the CD39 inhibitor POM-1 for $4 \mathrm{~h}$ prior to injection. The number of mice is 5 for each group and three independent experiments was performed. Log-rank (Mantel-Cox) Test for survival curve and unpaired t test for weight loss curve. ${ }^{* *} P<0.01$; ${ }^{* * * *} P<0.0001$. c The percentage of Foxp $3^{+} \mathrm{CD} 39^{+}, \mathrm{IL}-17 \mathrm{~A}^{+}$and IFN- $\gamma^{+}$in CD4 $+\mathrm{T}$ cells in spleen were measured by Flow Cytometry. The correlation between the frequency of CD39 ${ }^{+} /$ $\mathrm{CD}^{-}{ }^{-}$Treg and the score of aGVHD was calculated by Linear regression-compare slopes. Each symbol represents one mouse and three independent experiments were performed unpaired t test. ${ }^{*} P<0.05$; ${ }^{* *} P<0.01$; ${ }^{* *} P<0.001$. d CFSE-labeled Naïve CD4 + T cells were co-cultured with GMSCs and POM-1 + GMSCs induced Tregs at a 1:1 and 2:1 ratio in the presence of anti-CD3/CD28 mAb-conjugated beads for 3 days. Cells were stained with anti-mouse-CD4 antibody and the suppressive activity of various primed subsets on CFSE-labeled CD4 ${ }^{+}$cells is shown. Each symbol represents one independent experiments, unpaired t test. ${ }^{*} P<0.05 ;{ }^{* *} P<0.01$. e CFSE-labeled Naïve CD4 + T cells were co-cultured with

Foxp $3^{+} \mathrm{CD} 39^{+}$and Foxp $3^{+} \mathrm{CD} 39^{+}$at a 1:1 and 2:1 ratio in the presence of anti-CD3 mAb-conjugated beads and APCs for 3 days. Cells were stained with anti-mouse-CD4 antibody and the suppressive activity of various primed subsets on CFSE-labeled CD4 ${ }^{+}$cells is shown. Each symbol represents one independent experiments, unpaired $t$ test. ${ }^{*} P<0.01$; ${ }^{* *} P<0.001$. f The expression of CD25, CTLA-4, GITR, and CD62L were determined by Flow Cytometry and overlapped by Flowjo

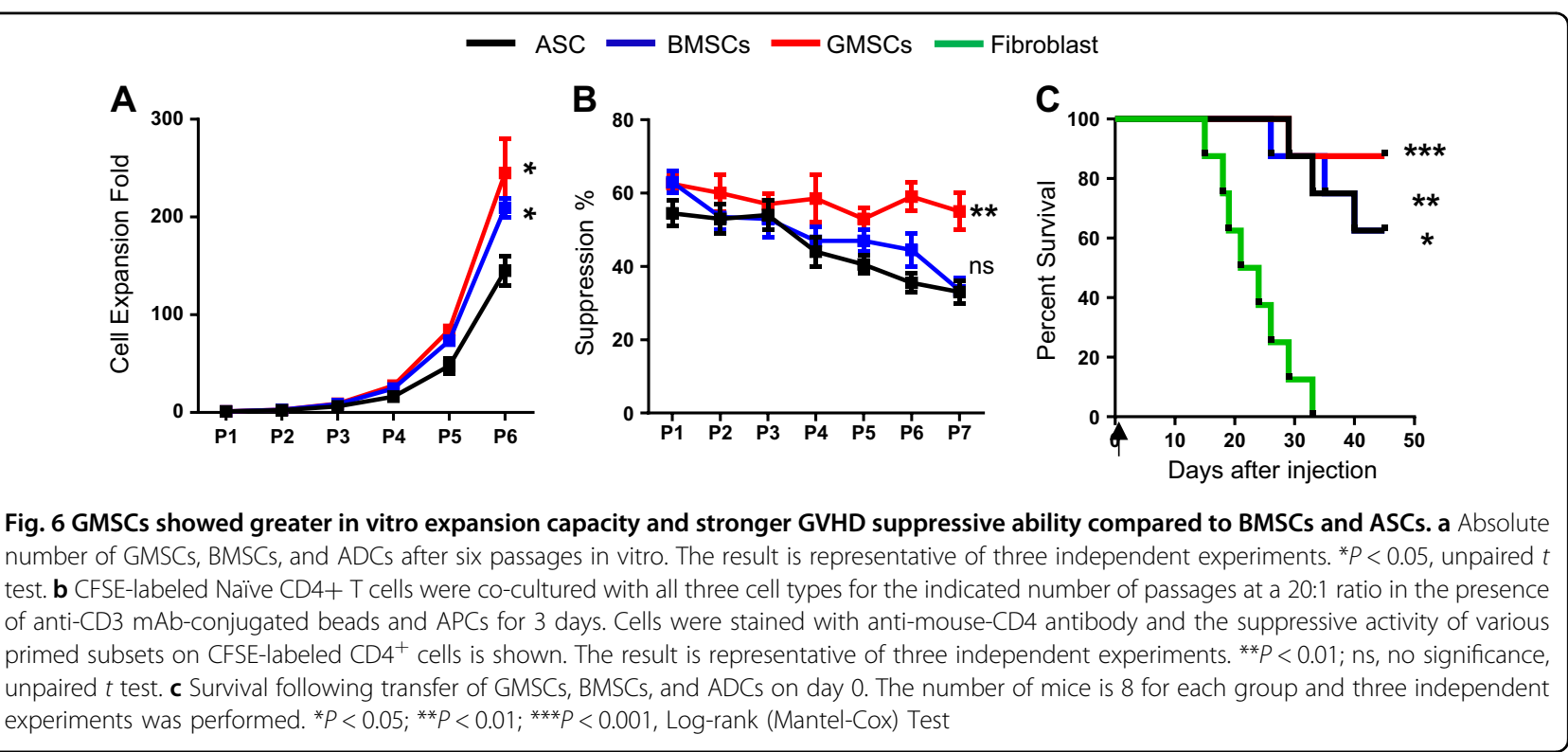

group was much longer. As MSCs may not be able to infiltrate organs of interest, it is possible that soluble factors secreted by GMSCs may regulate Treg cell function.

In our previous study, we found that GMSCs treated collagen-induced arthritis through the CD39 pathway ${ }^{22}$. We examined whether CD39 is also an important pathway for GMSC treatment in acute GVHD. Transferred GMSCs pretreated with CD39 inhibitor (POM-1) had a reduced therapeutic effect in acute GVHD. Recent studies shown that expression of CD39 on $\mathrm{CD} 4{ }^{+} \mathrm{CD} 25^{+}$Foxp $3^{+}$ Tregs catalyzes the sequential generation of adenosine by degradation of extracellular ATP/ADP to CD39 and conversion of 5 -AMP to CD73 ${ }^{40,41}$. These events lead to marked reduction in T-cell proliferation and secretion of pro-inflammatory cytokines. Herein, we demonstrated that GMSCs not only express CD39, but also increase the frequency of $\mathrm{CD} 39^{+} \mathrm{Foxp}^{+}$Tregs, which supports the generation of adenosine and promotes immune suppression of effector $\mathrm{T}$ cells in vitro and vivo.

Together, our data indicate that GMSCs have a greater potential therapeutic effect against acute GVHD than BMSCs or ASCs. Adoptive transfer of GMSCs provided the clinical outcome in our acute GVHD model using older passaged cells compared to these other mesenchyme stromal cell types. Efficiency of using older passaged cells means that more cells can be made available for treatment.

These experiments suggest that human GMSCs selectively promote the Foxp $3^{+} \mathrm{CD} 39^{+}$subset of iTregs. The ability of GMSCs to increase survival and reduce severity of acute GVHD appears to be associated with the upregulation expansion, differentiation of Tregs in vivo through the CD39 pathways. Human GMSCs present a novel therapeutic strategy for preventing and treating acute GVHD, as well as autoimmune diseases. Given the 
promising results outlined above, future studies in the clinic will be needed to assess the true prophylactic and therapeutic potential of this readily accessible and unique source of MSCs.

\section{Acknowledgements}

This work was supported by the National 863 project (NO. 2015AA020932), Natural Science Foundation of China (No. 81100270), Natural Science Foundation of China (No. 81571557), the Natural Science Foundation of Jiangsu (No. BK20131024) and International cooperation project of Jiangsu Province (No. BZ2011041).

\section{Author details}

'Hepatobiliary Center, First Affiliated Hospital, Jiangsu Key Laboratory of Xenotransplantation, Collaborative Innovation Center for Cancer Medicine, Nanjing Medical University, 211166 Nanjing, Jiangsu, China. ${ }^{2}$ State Key Laboratory of Reproductive Medicine, Nanjing Medical University, 211166 Nanjing, Jiangsu, China. ${ }^{3}$ Department of General Surgery, Second Affiliated Hospital, Nanjing Medical University, 210000 Nanjing, Jiangsu, China. ${ }^{4}$ Division of Blood and Marrow Transplantation, Department of Pediatrics, University of Minnesota Masonic Cancer Center, University of Minnesota, Minneapolis, MN 55455, USA

\section{Conflict of interest}

The authors declare that they have no conflict of interest.

\section{Publisher's note}

Springer Nature remains neutral with regard to jurisdictional claims in published maps and institutional affiliations.

Received: 20 April 2018 Revised: 18 November 2018 Accepted: 5 December 2018

Published online: 08 January 2019

\section{References}

1. Wang, D. et al. A CD8 T cell/indoleamine 2,3-dioxygenase axis is required for mesenchymal stem cell suppression of human systemic lupus erythematosus. Arthritis Rheumatol. 66, 2234-2245 (2014).

2. Yin, F. M. et al. Bone marrow mesenchymal stromal cells to treat tissue damage in allogeneic stem cell transplant recipients: correlation of biological markers with clinical responses. Stem Cells 32, 1278-1288 (2014).

3. Kurtzberg, J. et al. Allogeneic human mesenchymal stem cell therapy (remestemcel-L, Prochymal) as a rescue agent for severe refractory acute graftversus-host disease in pediatric patients. Biol. Blood Marrow Transplant. 20, 229-235 (2014).

4. Tang, L., Li, N., Xie, H. \& Jin, Y. Characterization of mesenchymal stem cells from human normal and hyperplastic gingiva. J. Cell. Physiol. 226, 832-842 (2011)

5. Michael, M., Shimoni, A. \& Nagler, A. Novel immunosuppression compounds and experimental therapies for chronic graft-versus-host disease. Acta Haematol. 130, 34-43 (2013).

6. Deaglio, S. et al. Adenosine generation catalyzed by CD39 and CD73 expressed on regulatory T cells mediates immune suppression. J. Exp. Med. 204, 1257-1265 (2007).

7. Gu, J. et al. Human CD39hi regulatory $T$ cells present stronger stability and function under inflammatory conditions. Cell. Mol. Immunol. 14, 521-528 (2017).

8. Yu, G. et al. Yield and characterization of subcutaneous human adiposederived stem cells by flow cytometric and adipogenic mRNA analyzes. Cytotherapy 12, 538-546 (2010).

9. Yu, G., Floyd, Z. E., Wu, X., Halvorsen, Y. D. \& Gimble, J. M. Isolation of human adipose-derived stem cells from lipoaspirates. Methods Mol. Biol. 702, 17-27 (2011).

10. Bucher, C. et al. IL-21 blockade reduces graft-versus-host disease mortality by supporting inducible T regulatory cell generation. Blood 114, 5375-5384 (2009).
11. Koenecke, C. et al. Alloantigen-specific de novo-induced Foxp3+Treg revert in vivo and do not protect from experimental GVHD. Eur. J. Immunol. 39, 3091-3096 (2009).

12. Canals, S., Larrosa, B., Pintor, J., Mena, M. A. \& Herreras, O. Metabolic challenge to glia activates an adenosine-mediated safety mechanism that promotes neuronal survival by delaying the onset of spreading depression waves. J. Cereb. Blood. Flow Metab. 28, 1835-1844 (2008).

13. Smith, K. M. et al. Effects of the selective adenosine A2A receptor antagonist, SCH 412348, on the parkinsonian phenotype of MitoPark mice. Eur. J. Pharmacol. 728, 31-38 (2014).

14. Pejman, L. et al. The effect of adenosine A2A and A2B antagonists on tracheal responsiveness, serum levels of cytokines and lung inflammation in guinea pig model of asthma. Adv. Pharm. Bull. 4, 131-138 (2014).

15. Mikus, E. G. et al. Interaction of SSR161421, a novel specific adenosine A(3) receptor antagonist with adenosine $\mathrm{A}(3)$ receptor agonists both in vitro and in vivo. Eur. J. Pharmacol. 699, 62-66 (2013).

16. Mikus, E. et al. Evaluation of SSR161421, a novel orally active adenosine A3 receptor antagonist on pharmacology models. Eur. J. Pharmacol. 699, 172-179 (2013).

17. $\mathrm{Gu}$, J. L. et al. TGF-beta-induced CD4+Foxp3+T cells attenuate acute graftversus-host disease by suppressing expansion and killing of effector CD8 +cells. J. Immunol. 193, 3388-3397 (2014).

18. Puliaev, R., Nguyen, P., Finkelman, F. D. \& Via, C. S. Differential requirement for IFN-gamma in CTL maturation in acute murine graft-versus-host disease. J. Immunol. 173, 910-919 (2004).

19. Via, C. S., Sharrow, S. \& Shearer, G. M. Role of cytotoxic T lymphocytes in the prevention of lupus-like disease occurring in a murine model of graft-vs-host disease. J. Immunol. 139, 10 (1987).

20. Puliaev, R. et al. CTL-promoting effects of CD40 stimulation outweigh B cellstimulatory effects resulting in $B$ cell elimination and disease improvement in a murine model of lupus. J. Immunol. 181, 47-61 (2008).

21. Chen, $\mathbf{M}$. et al. Adoptive transfer of human gingiva-derived mesenchymal stem cells ameliorates collagen-induced arthritis via suppression of Th1 and Th17 cells and enhancement of regulatory $\mathrm{T}$ cell differentiation. Arthritis Rheum. 65, 1181-1193 (2013).

22. Liang, Y. et al. IL-1beta and TLR4 signaling are involved in the aggravated murine acute graft-versus-host disease caused by delayed bortezomib administration. J. Immunol. 192, 1277-1285 (2014).

23. Zhang, P. et al. Induced regulatory $T$ cells promote tolerance when stabilized by rapamycin and IL-2 in vivo. J. Immunol. 191, 5291-5303 (2013).

24. Taylor, P. A. et al. Targeting of inducible costimulator (ICOS) expressed on alloreactive $T$ cells down-regulates graft-versus-host disease (GVHD) and facilitates engraftment of allogeneic bone marrow (BM). Blood 105 3372-3380 (2005)

25. Zeiser, R. et al. Preemptive HMG-CoA reductase inhibition provides graftversus-host disease protection by Th-2 polarization while sparing graft-versusleukemia activity. Blood 110, 4588-4598 (2007).

26. Park, M. J. et al. Blocking activator protein 1 activity in donor cells reduces severity of acute graft-versus-host disease through reciprocal regulation of IL17-producing T cells/regulatory T cells. Biol. Blood Marrow Transplant. 20, 1112-1120 (2014)

27. Waring, P. \& Mullbacher, A. Cell death induced by the Fas/Fas ligand pathway and its role in pathology. Immunol. Cell Biol. 77, 312-317 (1999).

28. Soloviova, K., Puliaiev, M., Foster, A. \& Via, C. S. The parent-into-F1 murine model in the study of lupus-like autoimmunity and CD8 cytotoxic T lymphocyte function. Methods Mol. Biol. 900, 253-270 (2012).

29. Montero, E. et al. Regulation of experimental autoimmune encephalomyelitis by $\mathrm{CD} 4+, \mathrm{CD} 25+$ and $\mathrm{CD} 8+\mathrm{T}$ cells: analysis using depleting antibodies. J. Autoimmun. 23, 1-7 (2004).

30. McHugh, R. S. \& Shevach, E. M. Cutting edge: depletion of CD4+CD25 +regulatory $T$ cells is necessary, but not sufficient, for induction of organspecific autoimmune disease. J. Immunol. 168, 5979-5983 (2002).

31. Hang, L. et al. Heligmosomoides polygyrus bakeri infection activates colonic Foxp3+T cells enhancing their capacity to prevent colitis. J. Immunol. 191, 1927-1934 (2013)

32. $\mathrm{Xu}, \mathrm{X}$. et al. Gingivae contain neural-crest- and mesoderm-derived mesenchymal stem cells. J. Dent. Res. 92, 825-832 (2013).

33. Zhang, Q. et al. Mesenchymal stem cells derived from human gingiva are capable of immunomodulatory functions and ameliorate inflammationrelated tissue destruction in experimental colitis. J. Immunol. 183, 12 (2009). 
34. Gonzalez, M. A., Gonzalez-Rey, E., Rico, L., Buscher, D. \& Delgado, M. Treatment of experimental arthritis by inducing immune tolerance with human adiposederived mesenchymal stem cells. Arthritis Rheum. 60, 1006-1019 (2009).

35. Huang, F. et al. Human gingiva-derived mesenchymal stem cells inhibit xenograft-versus-host disease via CD39-CD73-adenosine and IDO signals. Front. Immunol. 2, 68 (2017).

36. Liu, Y. et al. Therapeutic potential of human umbilical cord mesenchymal stem cells in the treatment of rheumatoid arthritis. Arthritis Res. Ther. 12, R210 (2010).

37. Haase, D., Starke, M., Puan, K. J., Lai, T. S. \& Rotzschke, O. Immune modulation of inflammatory conditions: regulatory T cells for treatment of GvHD. Immunol. Res. 53, 200-212 (2012).
38. Sattler, C. et al. Inhibition of T-cell proliferation by murine multipotent mesenchymal stromal cells is mediated by CD39 expression and adenosine generation. Cell Transplant. 20, 1221-1230 (2011).

39. Lee, J. J. et al. CD39-mediated effect of human bone marrow-derived mesenchymal stem cells on the human Th17 cell function. Purinergic. Signal. 10, 357-365 (2014)

40. Naamani, O., Chaimovitz, C. \& Douvdevani, A. Pharmacological preconditioning with adenosine $A(1)$ receptor agonist suppresses cellular immune response by an $\mathrm{A}(2 \mathrm{~A})$ receptor dependent mechanism. Int. Immunopharmacol. 20, 205-212 (2014).

41. Ohta, A. \& Sitkovsky, M. Extracellular adenosine-mediated modulation of regulatory T cells. Front. Immunol. 5, 304 (2014). 